\title{
LOS TORQUES DE PLATA DE MONASTERIO DE RODILLA
}

\author{
POR \\ BELÉN CASTILLO \\ Museo de Burgos
}

\author{
A la memoria \\ de la Dra. Mercedes Rueda Sabater
}

\section{RESUMEN}

Los torques de plata procedentes de Monasterio de Rodi1la (Burgos) constituyen un conjunto excepcional de la orfebrería prerromana de la Meseta Norte. Estas piezas, elaboradas con alambres trenzados y enrollados, responden a un proceso evolucionado en el que las influencias ibéricas y mediterráneas, transformadas por el gusto local, dan lugar a modelos propios y característicos de la orfebrería celtibérica.

\section{SUMMARY}

The silver torques coming from Monasterio de Rodilla (Burgos) are an excepcional ensemble of the jewellery before Roman times in the northern Meseta. These pieces, wrought of rolled up braiding wires, belong to a fully-developed process in which the Iberian and Mediterranean influences become transformed by the local style and give rise to special and typical models of the Celtiberic jewellery.

En 1985 ingresó en el Museo de Burgos un tesoro prerromano, integrado por tres torques de plata, adquirido por el Ministerio de Cultura, Dirección General de Bellas Artes y Archivos (O.M. de 27 de junio de 1985).

Por la información aportada por su vendedor sabemos, sin mayores precisiones, que las piezas provienen del entorno cercano al pueblo de Monasterio de Rodilla. En ese mismo entorno se conoce desde antiguo un importante yacimiento arqueológico situado en el cerro Alto de Rodilla, junto a la actual autopista A-1. En este yacimiento, aunque nunca se ha excavado, se han efectuado numerosas y continuas prospecciones (Abásolo, 1975, 86-88) que han permitido constatar una densa ocupación romana, con abundantes hallazgos materiales de cerámica común, terra sigillata, restos musivos y epigráficos (González Salas, 1953, 226; Osaba, 1962, 261; Alonso, 1972, 210 ss.; Abásolo, Alonso, Sainz, 1982, 163). Por su situación geográfica, dentro del recorrido de las vías de comunicación romanas Ab Asturica-Burdigalam y Ab Asturica-Tarracone (Abásolo, 1975, 86), ha sido identificado con la mansión de Tritium Autrigonum. Como tal aparece recogida en el Itinerario Antonino, que la localiza entre las de Deobrigula y Virovesca, y en otras fuentes literarias como la Naturalis Historiae de Plinio (IV, 3, 27) que la cita entre las ciudades más importantes de los autrigones (Historia de Burgos I, 1985, 224 y 231 ).

Otros hallazgos arqueológicos, clasificados en etapas culturales prerromanas, son las cerámicas a torno celtibéricas, las cerámicas a mano, los útiles de sílex, los molinos, etc.; a ellos debemos añadir, además, una pequeña arracada de oro, conservada actualmente en la Colección Fontaneda (Luis Monteverde, 1969, 228; Castillo, 1985, 250-251) y una fíbula en omega de plata, donada al Museo de Burgos ${ }^{1}$.

A la vista de estos datos, fruto de hallazgos casuales y de la prospección, parece que el yacimiento conocido como Alto de Rodilla tuvo una secuencia importante de poblamiento claramente constatada, al menos durante la Edad del Hierro y en época romana. Por ello pensamos que no es desacertado considerar la hipótesis de que estos torques estén asociados al mismo o incluso que ésta sea su procedencia.

\section{INVENTARIO}

En nuestro caso y debido a que los torques 1 y 2 tienen las mismas características formales y técnicas, hemos considerado oportuno hacer una única descripción, señalando de manera independiente los datos que los diferencian, concretamente los relativos a medidas y peso.

Torques 1 (fig. 1): plata; diám. 21'15-19'9, ancho 2'3, grosor 0'6-0'3 cm; peso 253'60 gr; Museo

1 Inédita. Fíbula de plata tipo «omega». Consta de un aro abierto cuyos extremos, vueltos hacia atrás, se rematan en sendas esferas con un botoncito. Las zonas donde doblan están decoradas con dos esferas dispuestas una en la cara superior y otra en la inferior. Diám. 2'2, ancho 2'4, grosor 0’3 cm, peso 4'26 gr; Museo de Burgos, $\mathrm{n}^{\circ}$ inv. 8.608. 


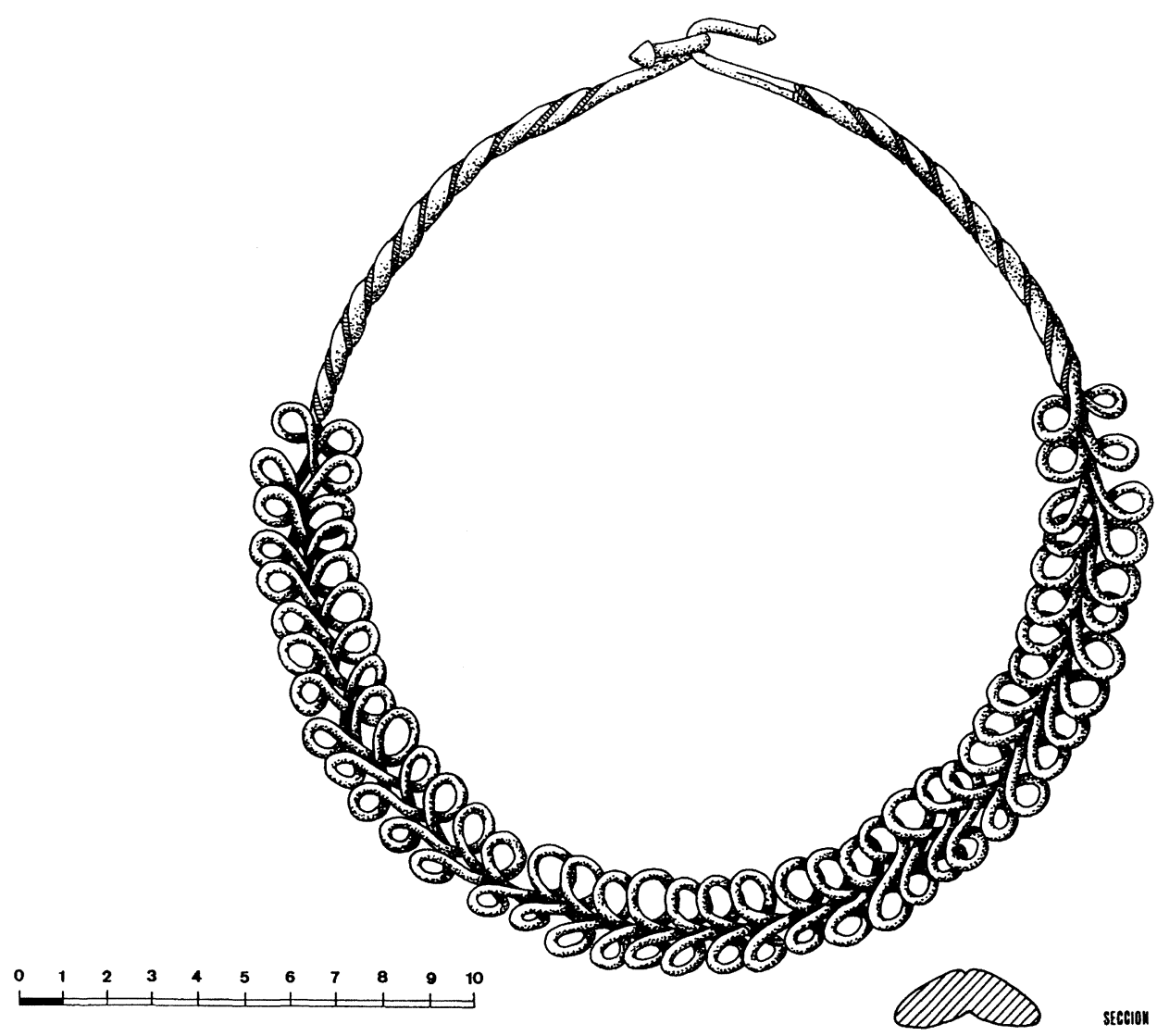

Figura 1.-Torques $\mathrm{n}^{\mathrm{o}} 1$.

de Burgos, $n^{o}$ inv. 8.513. (I Celti, 1991, 738, $n^{o}$ 477).

Torques 2 (fig. 2): plata; diám. 16-15'5, ancho 2'2, grosor 0'5- 0'4 cm; peso 161'80 gr; Museo de Burgos, $n^{\circ}$ inv. 8.514 .

Ambas piezas pertenecen al tipo de torques denominado de alambres enrollados. Constan de una varilla flexible realizada con dos alambres de sección circular, en la que los extremos se funden en un solo doblez en forma de gancho, que es su tipo de cierre. La varilla se divide en tres sectores perfectamente diferenciados por estar trabajados con dos técnicas distintas. El central, de mayor anchura que los otros dos, tiene los alambres trenzados en lazos alternos, cuya unión da lugar a un motivo de ochos seriados unidos en su parte media con una espiga muy marcada, siendo su sección triangular y aplanada. Las zonas extremas se trabajan mediante un enrollado funicular de los alambres, recorrido en sus juntas por un hilo retorcido. La sección es, en estos sectores, circular, y la varilla pierde grosor hasta fundirse en un solo alambre facetado doblado en gancho. Los extremos se decoran con botones cóni- cos como remate final. El torques $\mathrm{n}^{\circ} 2$ no los conserva.

Torques 3 (fig. 3): plata; diám. 12'5-11'5, ancho 1'9, grosor 0'4- 0'3 cm; peso $52 \mathrm{gr}$; Museo de Burgos, $n^{\circ}$ inv. 8.515.

Pertenece al tipo de torques denominado de alambres enrollados. Consta de una varilla flexible realizada a partir de la unión de tres alambres de sección circular. En el centro se dispone un nudo de Hércules, a partir del cual los hilos se enrollan en sentido funicular. La sección de la varilla es redonda y su grosor decrece hacia los extremos, en los que los alambres se funden en uno solo doblado en gancho para cerrar la pieza. Estos se decoran con sendos botones cónicos como remate final.

Los torques muestran una elaboración cuidada, por ello pensamos que los alambres fueron obtenidos mediante un procedimiento de trefilado, técnica conocida en la antigüedad aunque su uso no se hace extensivo hasta la Edad Media (Formigli, 1983, 326). El trefilado pudo completarse en zonas concretas con un trabajo mecánico en frío, para finalmente realizar el acabado con un pulido superficial. 


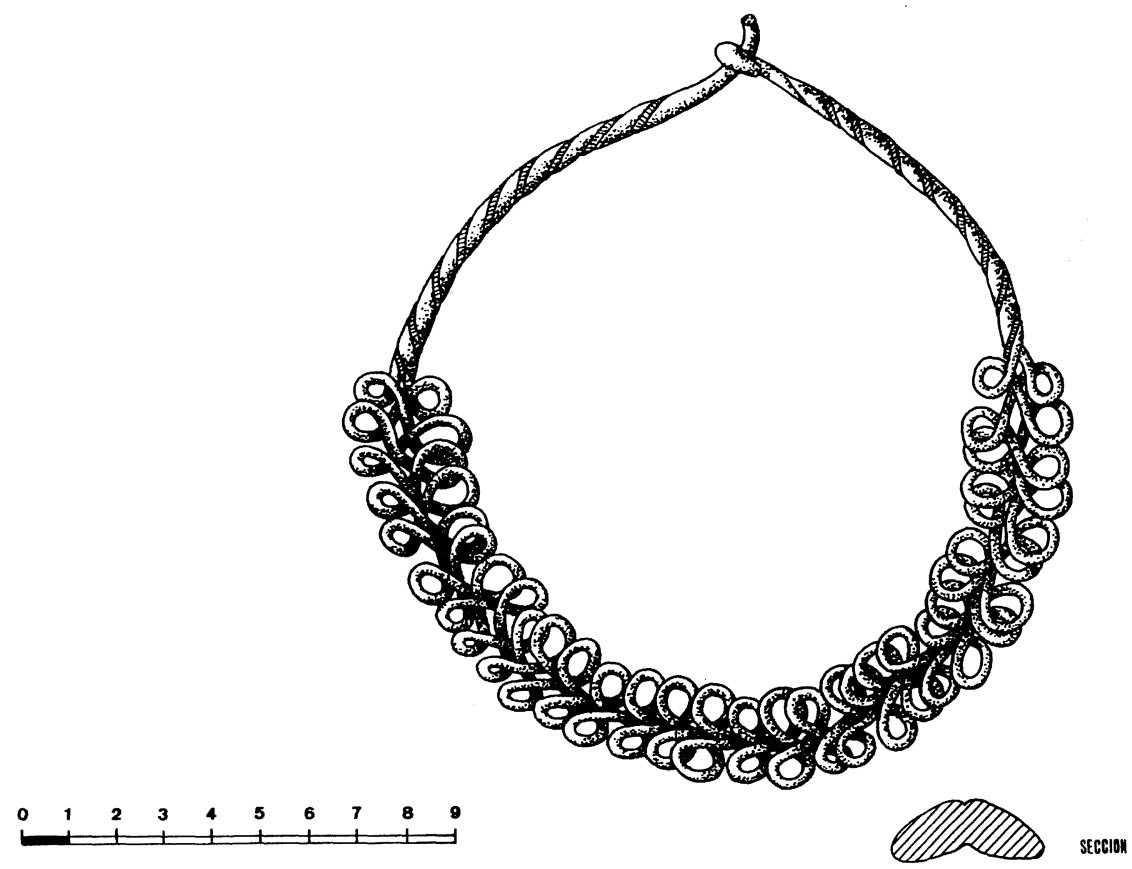

Figura 2.-Torques $n^{\circ} 2$.

Este último proceso posiblemente se hizo mediante un sistema de abrasión controlada, según se deduce de la observación de las piezas con lente binocular de 45 aumentos. Una característica común en todas ellas es la elasticidad de sus varillas, sobre todo las de $\operatorname{los} n^{\circ} 1$ y 2 . Su estado de conservación es muy

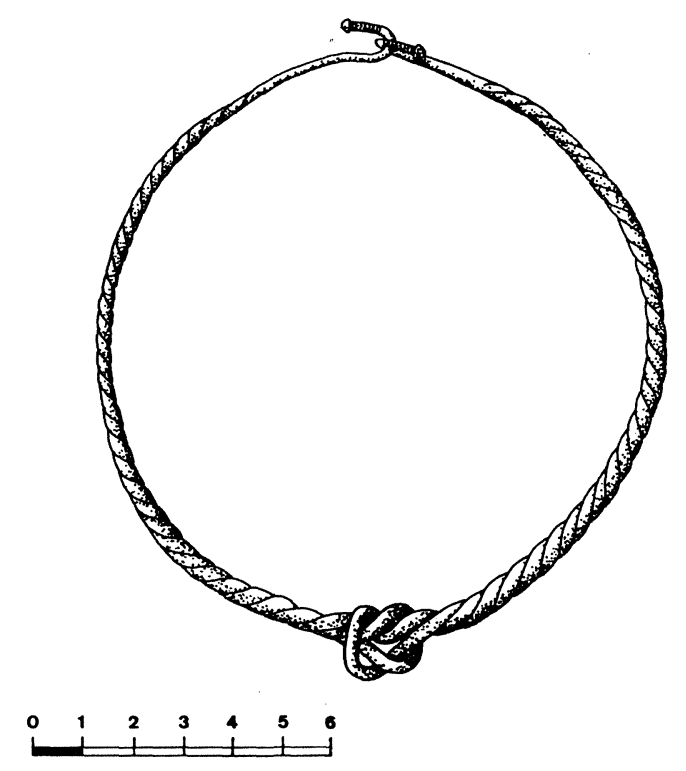

Figura 3.-Torques $\mathrm{n}^{\circ} 3$. bueno, no presentando huellas de dobleces o roturas, salvo la pérdida de los botones terminales del torques $\mathrm{n}^{\circ} 2$, por lo que creemos que la ocultación debió realizarse con sumo cuidado y, quizás, cuando ésta se produjo estaban en pleno uso.

\section{ESTUDIO DE LAS PIEZAS}

El tesoro de Monasterio de Rodilla es un hallazgo más a añadir a los ya conocidos de la orfebrería prerromana de la Meseta Norte. Su presencia en un área relativamente marginal y algo alejada de la estricta cuenca del Duero es un buen indicativo de la expansión de esta orfebrería y su fuerte arraigo por todo el territorio.

Desde el punto de vista morfológico estos torques mantienen una estrecha relación con otras producciones de la Meseta. Así los paralelos más cercanos los encontramos en los torques elaborados con alambres enrollados de los tesoros de Palencia (Almagro Basch, 1960, 39-40; Raddatz, 1969, 233, Taf. 34.2); Valladolid (Mañanes, 1983, 154; Delibes, Esparza, Martín Valls, Sanz Mínguez, 1993, p. 397 ss.) o Zamora (Delibes, Martín Valls, 1981, 153-155; Idem, 1982; Esparza, 1983, 39-46; Elorza, 1992). Sin duda alguna la pieza que presenta mejores paralelos, en todos los casos, es la $\mathrm{n}^{\circ} 3$, es decir el torques decorado con el nudo de Hércules. 
Común a todo el conjunto procedente de Monasterio de Rodilla es el uso de la técnica de alambres enrollados en sentido funicular y el sistema de cierre en ganchos. Esta técnica llegó a tener una gran difusión en la orfebería antigua de la Península (Raddatz, 1969), y en el caso concreto del mundo ibérico es uno de los adornos más reproducidos en la plástica de sus damas oferentes (Tarradell, 1968). En la Meseta Norte es igualmente un modelo habitual en la práctica totalidad de los atesoramientos prerromanos de época tardía que, en mayor o menor número, incluyen casi siempre torques de alambres enrollados. Buen ejemplo de ello, además de los ya citados, son los torques abulenses de El Raso de Candela (Fernández Gómez, 1979, 380) o el fragmento, procedente de un hallazgo casual, de Cerezo de Río Tirón en Burgos ${ }^{2}$.

El sistema de cierre en forma de gancho rematado con pequeños botones (fig. 4) es el utilizado por
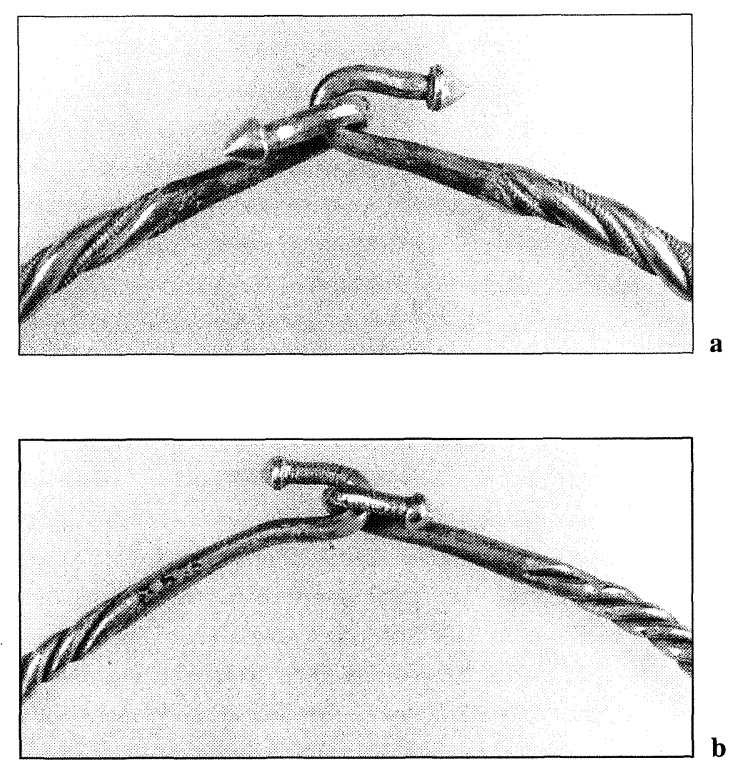

Figura 4.-Cierres de gancho; a) torques $\mathrm{n}^{\circ} 1$, b) torques $\mathrm{n}^{\circ} 3$

los tres torques de este tesoro. El tipo de cierre en ganchos está muy extendido en la Meseta, siendo habitual en los torques con varillas de escaso desarrollo volumétrico, como, por ejemplo, los decorados con nudo de Hércules, lazos u ochos de Palencia, Padilla de Duero y Arrabalde I. Esta asociación entre este tipo de torques y un sistema de cierre tan

2 Fragmento del extremo de un torques de plata con cierre de gancho. Los alambres se unen en un solo junco que, probablemente, se remataba en forma de gancho. Long.: 5 $\mathrm{cm}$; grosor: 0'3 cm; depositado en el Museo de Burgos. específico es, quizás, un elemento a tener en consideración a la hora de evaluar las características propias que definen la orfebrería prerromana de la Meseta, máxime si nos atenemos al alto y significativo porcentaje de piezas en que esta unión se produce.

En la orfebrería ibérica observamos, igualmente, un hecho similar en relación a los cierres de los torques. En este caso, es el cierre en ojales el modelo más común y de más amplia difusión. Su presencia se constata, atendiendo a la clasificación propuesta por Raddatz (1969, 18-21), en los grupos del Tajo, Andalucía y Cuenca, además de en el tesoro de Tivisa. Los torques con cierres de ojales se corresponden, en general, con varillas de alambres - bien sean trenzados o enrollados- de mayor desarrollo volumétrico, siendo más raro, aunque no por ello inexistente, su presencia en varillas lisas.

Si como hemos señalado para ambos tipos de cierres -en gancho y en ojales- existe una clara dispersión geográfica, correspondiente el primer tipo a la Meseta Norte y el segundo a la extensa área de la cultura ibérica, su presencia en las dos zonas, aunque en número notablemente inferior al modelo propio que las define, es posiblemente un elemento indicativo de la permeabilidad cultural de estas poblaciones. Así la escasa representación del cierre en gancho en el mundo ibérico - dos torques del tesoro jienense de Menjíbar y otro en la localidad pacense de Orellana la Vieja (Raddatz, 1969, Taf. 25-8; 26-1 y 33-1)-, corre paralela a la del cierre en ojales en la Meseta Norte - un ejemplar en el tesoro de Arrabalde I y otro en el abulense de el Raso de Candeleda, éste último considerado por Fernández $(1979,403)$ como una importación de talleres andaluces, a través de la «vía de la plata».

Un aspecto muy interesante de los torques de Monasterio de Rodilla es el relativo a su decoración. Dos son los motivos decorativos que caracterizan estas piezas: uno el denominado nudo de Hércules y el otro los ochos seriados. Cada uno de ellos cuenta con representaciones, más o menos cercanas, en la orfebrería de la Meseta y, en ambos casos, son también deudores de influencias externas.

Los torques decorados con el nudo de Hércules (fig. 5) son piezas que, aunque de muy sencilla ejecución sobre todo estructuralmente, contituyen un conjunto interesante en la orfebrería de la Meseta. Responden a un mismo modelo de fabricación (fig. 6) y hasta la fecha su distribución geográfica se circunscribe, casi con exclusividad, a este ámbito territorial (fig. 7). Este hecho, frente al único ejemplar ibérico conocido del tesoro de Menjíbar (Raddatz, 1969, Taf. 34.2), ha planteado la hipótesis de 

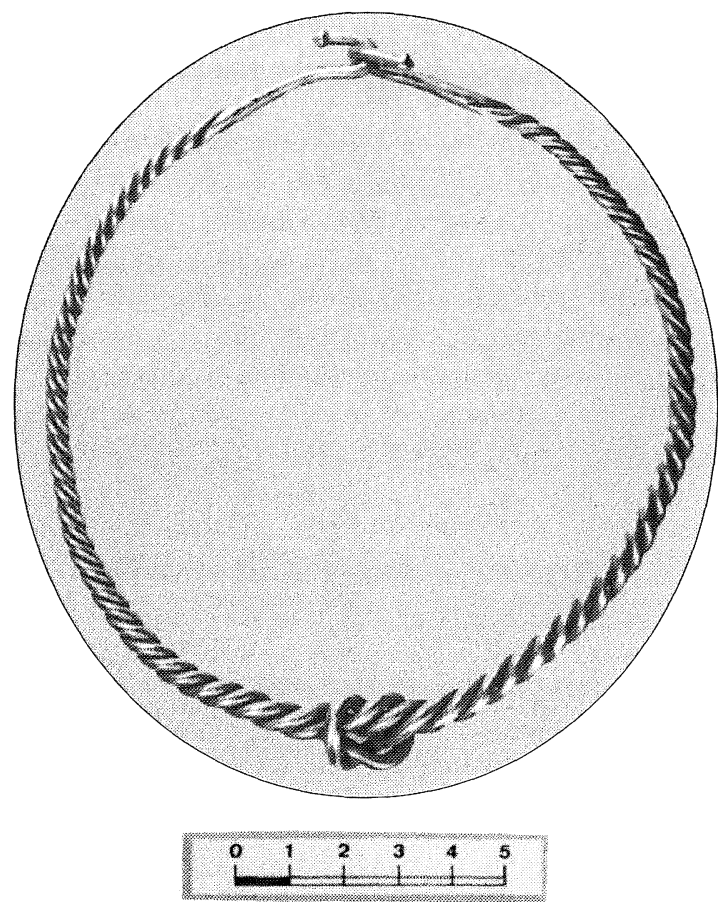

Figura 5.-Torques $\mathrm{n}^{\circ} 3$.

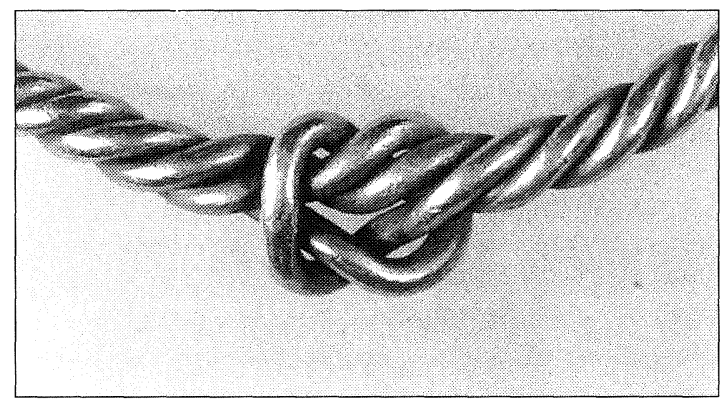

Figura 6.-Torques $\mathrm{n}^{\circ} 3$, detalle del nodus herculeus.

considerarlos producciones genuinamente meseteñas, valorando su presencia en territorios ajenos a la misma como resultado de las relaciones comerciales entre ambas regiones (Delibes, Esparza, Martín Valls, Sanz Mínguez, 1993, 427).

El nudo de Hércules se documenta en la Península a partir del s. IV-III a. C., en los broches de Cádiz y de Galera y como elemento decorativo en algunas fíbulas anulares del Levante y de la Meseta (necrópolis de la Mercadera, Soria). Su presencia se ha vinculado a influencias mediterráneas, concretamente Nicolini $(1990,243)$ considera a los gaditanos producciones locales ejecutadas a partir de modelos griegos, a pesar de que algunos ejemplares como el de la Mercadera, por su decoración figura- da de cabezas humanas, se relacionen con el período antiguo de La Tène (Taracena, 1934, 170). Para los nudos de los torques se ha mantenido también esta misma filiación mediterránea y más exactamente helenística; así Raddatz $(1969,104)$ piensa que pueden derivar de los que decoran las diademas de tipo Kerch, y Delibes, Esparza, Martín Valls y Sanz Mínguez $(1993,427)$ los relacionan, además, con producciones suritálicas ${ }^{3}$. Sin redundar de nuevo en los paralelos, aspecto ya tratado con ocasión de los torques de Padilla de Duero, sí nos gustaría hacer referencia a un brazalete de plata fechado entre el 350 - 300 a. C., hallado en Acarnania (Grecia) (Williams, Ogden, 1994, 73), cerrado por un sencillo nudo de concepción similar a los de los torques peninsulares -ibéricos o meseteños-. Una solución semejante aparece en el cierre de una pulsera de oro, datada en el s. III a. C., procedente de Villaricos (Nicolini, 1990, núm. 146).

La presencia de este nuevo ejemplar burgalés, con nudo de Hércules y cierre de ganchos, apoya la ya expresada opinión de su producción meseteña y la particularidad de su tipo, de igual manera que también se le reconoció a los torques sogueados con voluminosos remates en forma de perilla, los decorados con lazos o bucles y los decorados con ochos (Delibes, Esparza, 1989, 112-113).

Los dos torques restantes son piezas notables en la orfebrería prerromana de la región (figs. 8 y 9). En ellos se concretan dos tradiciones plenamente asentadas en la Península, por una parte el sogueado y por otra el trenzado de alambres -éste último, sin duda, es una técnica peculiar y propia de la orfebrería ibérica (Fernández Gómez, 1985, 183)-. La conjunción de ambos aspectos en una sola pieza los dota de unas características especiales que los singulariza en relación a la orfebrería prerromana conocida hasta la fecha.

Curiosamente sólo conocemos otro ejemplar con doble técnica de elaboración. Se trata de un torques del tesoro de Arrabalde I (Delibes, Martín Valls, 1982) ejecutado con alambres enrollados y cierre de ganchos y decorado en su parte central con un trenzado de disposición longitudinal bastante compacto. Tanto en un caso como en otro, Arrabalde I y Monasterio de Rodilla, los torques responden a un mismo concepto morfológico, si bien se diferencian por la forma del trenzado de sus zonas medias. En el primer caso los alambres se cruzan, mientras

${ }^{3}$ Estos autores realizan un exhaustivo estudio sobre este motivo decorativo en la Península. Analizan sus precedentes, su relación con la cultura helenística y las posibles rutas de penetración, tanto a través del Mediterráneo, como por la vía terrestre del mundo celta. 


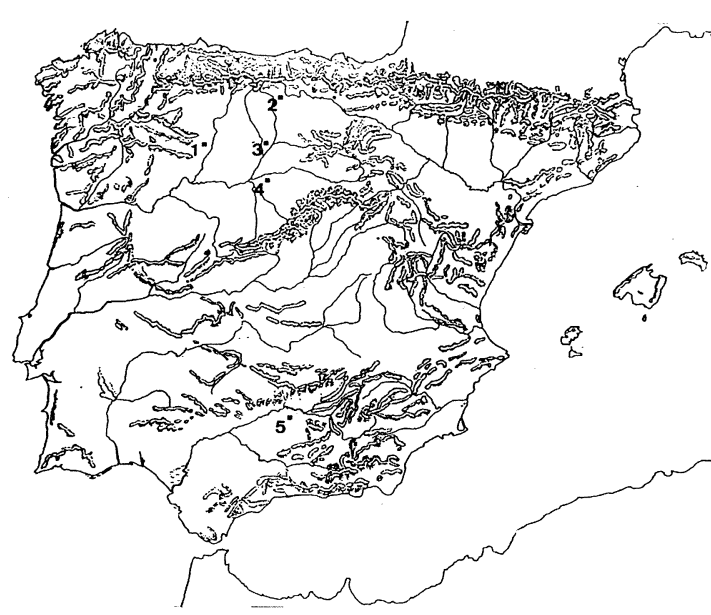

Figura 7.-Península Ibérica: dispersión de los torques decorados con nudos de Hércules. 1, Arrabalde (Zamora); 2 , Monasterio de Rodilla (Burgos); 3, Palencia; 4, Padilla de Duero (Valladolid); 5, Menjíbar (Jaén).

que en el segundo forman lazos alternos, en ambos sentidos, dando lugar su unión a una banda continua de ochos seriados, a modo de hojas superpuestas.

Los torques más antiguos de varillas trenzadas son los de los tesoros levantinos de Cheste (Valencia) y de Jávea (Alicante) (Mélida, 1902, 184 y 1905, 366; Almagro Gorbea, 1989; Perea, 1991, 218). Estas piezas, aunque pertenecientes a conjuntos diferentes, han sido datadas por Nicolini (1990, 478) a mediados del s. IV a.c., si bien su momento de ocultación fue posterior situándose a finales del s. III a. C. (Raddatz, 1969, 52 ss.). De estructura similar a la de los torques de Jávea son los ejemplares sevillanos de los tesoros de Mairena del Alcor y la Puebla de los Infantes (Fernández Gómez, 1985, $183 ; 1989,84)$. En ambos casos las piezas, fechadas a principios del s. III a. C., están entrelazadas en ondas dando lugar a varillas caladas, de sección romboidal las de Mairena del Alcor y casi plana las de la Puebla de los Infantes, cerradas en ojales.

La consideración del trenzado de alambres como una característica propia y genuina de la orfebrería ibérica (Fernández, 1985, 166) ha sido matizada por Nicolini $(1990,476)$ al plantear que pudo desarrollarse a partir de ciertos modelos helenísticos que fueron adaptados, según su gusto y conocimientos técnicos, por orfebres hispánicos. Citaremos, por ejemplo, el cetro aparecido en la Tumba degli Ori de Canosa, en Tarento, fechado en la segunda mitad del s. Iv a. C. (Williams, Ogden, 1994, 203) y un collar realizado con cuentas tubulares, fechado a finales del s. III a. C., que se conserva en Richmond, en el Museo de Virginia (Deppert-Lippitz, 1985, 218). A lo largo de la centuria siguiente se mantienen los alambres trabajados en retícula, pero su uso se reduce a mero elemento decorativo de filigrana aplicada sobre un soporte, caso de una diadema de Kerch, adornada con un gran nudo de Hércules decorado con granates, y un fragmento de brazalete, rematado en cabezas de antílopes, de la zona de Tesalia (Deppert-Lippitz, 1985, 246 y 266). Otras producciones helenísticas son algunos collares o brazaletes elaborados con una sencilla cadena de grandes eslabones unidos en espiga, tipo loop-inloop, como el procedente de la zona de Capua rematado con sendas cabezas de león y fechado en el año 300 a. C. (Williams, Ogden, 1994, 216). La datación de algunos de estos objetos en la segunda mitad del s. IV a. C. y a lo largo del s. III a. C., los sitúa cronológicamente en fechas cercanas a las piezas levantinas y andaluzas y la localización suritálica de varios de ellos apoya, en cierta manera, la opinión de Nicolini sobre la posible inspiración en modelos helenísticos.

El trenzado de alambres, al igual que el enrollado funicular, pudo muy bien deberse a influencias mediterráneas. Sin embargo, en este caso, creemos que hay que tener también en consideración otra técnica muy peculiar y bien representada en la orfebrería antigua del sur y levante español: nos referimos concretamente a la filigrana al aire.

Aunque no son especialmente numerosos los ejemplares elaborados con esta técnica debemos hacer mención, a propósito de ella, de dos arracadas, una procedente de Cádiz - I B-y la otra del yacimiento alicantino de la Condomina (Perea, 1991, 151-152). La pieza gaditana, para la que Nicolini da la procedencia de Puerta de Tierra (1990, 340 ), es en este sentido la más significativa debido a su filigrana trabajada en ondas, procedimiento que coincide en cierta manera con el seguido por los torques de Jávea, Mairena del Alcor y Puebla de los Infantes. Sin duda alguna la diferente cronología entre ambas producciones - la arracada gaditana ha sido fechada entre el final del s. vil a C. y mediados del s. vi (Fase Media en la sistematización de Perea dentro del Período de Influencias Coloniales: 1991, 210) y en la primera mitad del s. vi a. C. por Nicolini, frente a la datación a mediados del s. IV y el s. III a. C. de los torques- puede plantear dudas sobre su validez como modelo de inspiración.

La filigrana al aire no es, como el trenzado, una técnica de exclusiva representación peninsular. Por el contrario, de ella existen buenos ejemplos en la orfebrería etrusca fechables entre el último cuarto del s. viII y el vir a. C. aunque, en este caso como 


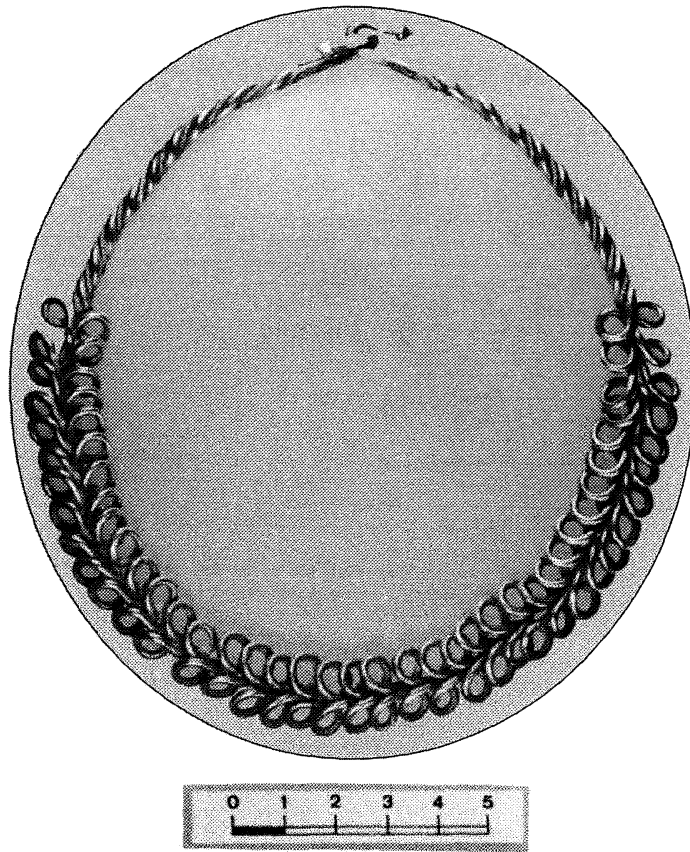

Figura 8.-Torques $\mathrm{n}^{\mathrm{o}} 1$.

en el de las arracadas, alejados cronológicamente de la datación de los torques. Curiosamente la filigrana al aire aparece también trabajada en ondas en los brazaletes en espiral -modelo bien representado en la orfebrería ibérica y de la Meseta Norte- de las necrópolis de Bisenzo, Marsiliana d'Albegna o Cerveteri (Cristofani, Martelli, 1983, 252, 266 y 275); en ondas unidas a bandas laminares, en una fíbula serpentiforme de la tumba de Perazzeta en Marsiliana (Idem, 267), en un pendiente o pequeño brazalete de Vulci (Idem, 276) y en una aguja o adorno de vestido de Narce, en la necrópolis de Monte Cerreto (Idem, 284). Ésta última con la peculiaridad de que su banda central de filigrana al aire es de lazos alternos, que bien podríamos considerarlo como el esquema simplificado del trenzado de los torques burgaleses.

Es sin duda dentro de este marco mediterráneo donde se dan las bases para la aparición de la técnica del trenzado de alambres que bien pudo desarrollarse a partir de los modelos helenísticos de retícula calada o de la filigrana al aire ${ }^{4}$. Será, sin

\footnotetext{
4 En opinión de Perea $(1991,204)$ considerar esta técnica como un elemento prestado de la orfebrería etrusca puede resultar precipitado a pesar de su cronología anterior, porque las influencias técnicas, decorativas o iconográficas en las producciones de la Península, aunque frecuentes, son de valoración compleja por la discontinuidad con que aparecen registradas a lo largo del tiempo.
}

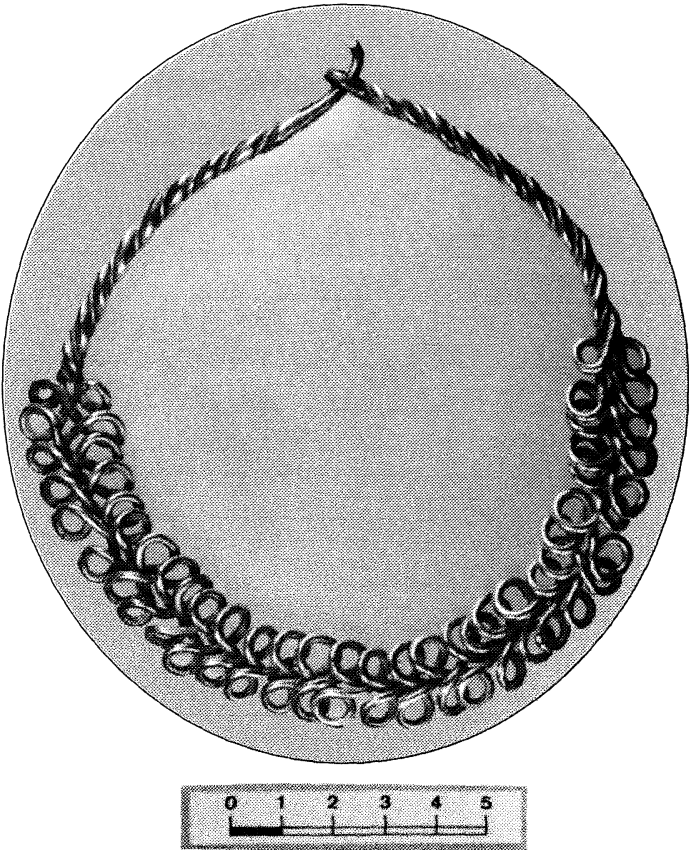

Figura 9.-Torques $n^{\circ} 2$.

embargo, la cultura ibérica la que la dote de una personalidad propia y definida con piezas singulares de su producción y la que, con posterioridad, creará otras versiones con características específicas dentro de su ámbito cultural y en sus áreas de influencia, caso por ejemplo de la Meseta Norte (fig. 10).

A una etapa más avanzada de la cultura ibérica pertenecen los torques de alambres trenzados de los tesoros jienenses de Los Villares (Raddatz, 1969, 296 - no 2) y de Menjíbar (Idem, 1969, 227 - n 11 y 12), fechados en el s. II a.C. (Idem, 1969, 46). Estas piezas quizás debamos considerarlas, por situación y cronología, el «hilo conductor» de la técnica del trenzado hacia las áreas del interior y norte peninsular. Común a todos ellos son las varillas fusiformes y los extremos rematados en ojales, diferenciándose por el tipo de trenzado. Así en uno de los torques de Menjíbar (Idem, 1969, Taf. 25.7) los alambres están cruzados a modo de eslabones, de manera muy similar al torques de Cheste, mientras que los otros dos (Idem, 1969, Taf. 4.2 y 26.3) se trabajan en ondas unidas por un cordoncillo sogueado.

Será el trenzado de alambres cruzados - semejando eslabones - el que encontremos en un fragmento de torques del tesoro de Drieves (Guadalajara) (Raddatz, 1969, $215 \mathrm{n}^{\circ} 132$ ), a medio camino entre el Levante y la Meseta, y en dos torques de los tesoros de Arrabalde I y II (Delibes, Martín Valls, 


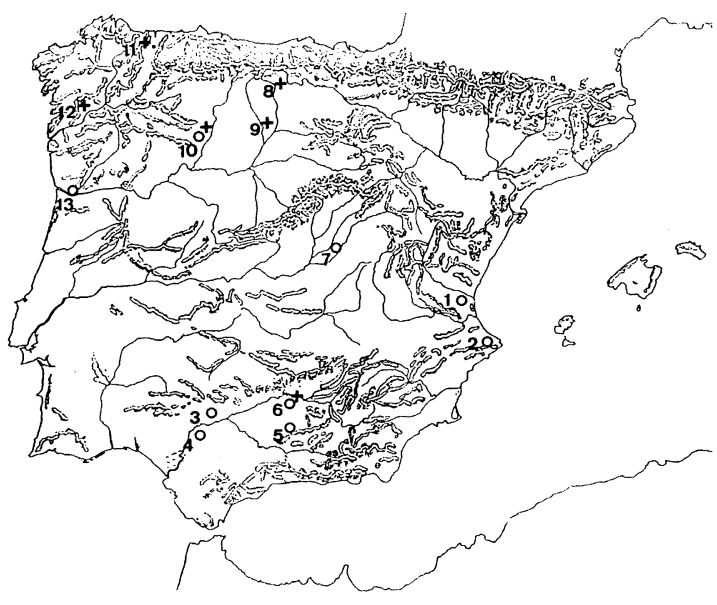

Figura 10.-Península Ibérica: dispersión de los torques con varillas de alambres trenzados $(+)$ y de los torques decorados con lazos y ochos (o). 1, Cheste (Valencia); 2, Jávea (Alicante); 3, Puebla de los Infantes (Sevilla); 4, Mairena del Alcor (Sevilla); 5, Los Villares (Jaén); 6, Menjíbar (Jaén); 7, Drieves (Guadalajara); 8, Monasterio de Rodilla (Burgos); 9, Palencia; 10, Arrabalde (Zamora); 11, Mondoñedo (Lugo); 12, Cruceiro da Coruña (La Coruña); 13, Bagunte (Portugal).

1982; Delibes, Esparza, 1989, 108; Elorza, 1992, 30). Éstos últimos muestran algunas variantes con respecto a los ejemplos anteriores, siendo su trenzado más compacto, parecido en cierta manera al motivo en espiga del brazalete de Jávea (Nicolini, 1990, 514). El trenzado en espiga aparece en la Meseta en las cadenillas de Roa, Palencia (Castillo, 1986, 252) y Padilla de Duero (Delibes, Esparza, Martín Valls, Sanz Mínguez 1993, 402) y en las piezas - adornos para el pelo- de Saldaña (Herrero, 1969, 231), Sasamón (Castillo, 1986, 250; Esparza, 1988,145 , que la define como una posible arracada) y Arrabalde (Delibes, Martín Valls, 1982). Estos trabajos de alambres cruzados son bastante complejos, en ellos se combina el gusto por lo decorativo y una cierta flexibilidad de las piezas. Este mismo concepto es, sin duda, el que debemos aplicar al trenzado de los torques burgaleses, si bien su peculiaridad reside en la sencillez de la técnica empleada que tiende hacia una varilla plana y ancha conseguida a partir de dos alambres trenzados en lazos alternos (figs. 11 y 12).

El motivo de lazos u ochos está perfectamente integrado en las producciones celtibéricas, de tal manera que se les considera como un diseño exclusivo de la Meseta (Delibes, Esparza, 1989, 113), siendo los tesoros palentinos del Cerro de la Miranda (Almagro Basch, 1955-57, 39 ss.) y de las Filipenses (Raddatz, 1969, tesoro III, 233-237) los que aportan el mayor número de ejemplares con esta decoración. Su disposición puede ser unitaria o múltiple, en el centro o a lo largo de la varilla, y puede ser un lazo simple o doble, denominado ocho. Desde el punto de vista morfológico los torques decorados con lazos u ochos son prácticamente iguales a los decorados con el nudo de Hércules con sus varillas de alambres enrollados -helicoidales-, en ocasiones también lisas, no muy voluminosas, pero con ligero engrosamiento central y extremos cerrados con ganchos.

La dispersión de estos torques se circunscribe prácticamente a la Meseta Norte, que es, también por el momento, la región que mayor número de piezas aporta. Por el contrario, los ejemplos conocidos fuera de ella los encontramos de nuevo en un torques del tesoro de Menjíbar (Raddatz, 1969, Taf. $25,26)$, y en el NW peninsular, en una pieza de Mondoñedo (Lugo) (Idem, 1969, Taf. 27), otra en Cruceiro da Coruña (La Coruña) (López Cuevillas, 1951, 31), y en el tesoro portugués de Bagunte, cerca de Oporto (Idem, 1951, 38, fig. 28.7). Los tres primeros responden al modelo de alambres enrollados decorados con ochos y cierres de ganchos, mientras que el cuarto - el portugués de Baguntees un torques de alambres trenzados. Al igual que ocurría con los torques decorados con nudos de Hércules, los de lazos y ochos muestran también una significativa dispersión meseteña y los ejemplares externos a ella parecen responder a exportaciones de esta orfebrería. Este aspecto, con respecto al NW, abre nuevas perspectivas sobre la valoración

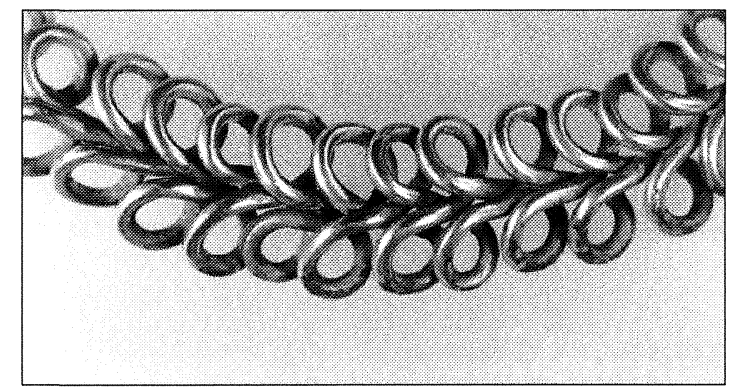

Figura 11.-Torques $\mathrm{n}^{\circ} 1$, detalle del trenzado central.

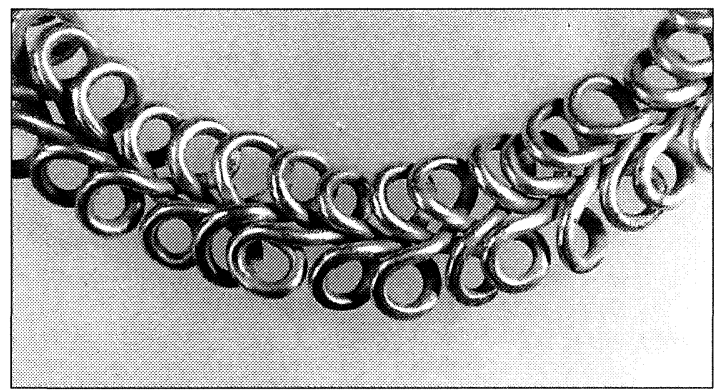

Figura 12.-Torques $\mathrm{n}^{\circ} 2$, detalle del trenzado central. 
de las corrientes de influencias entre ambas producciones, fundamentalmente planteadas en una sola dirección como elementos cedidos a la Meseta, caso por ejemplo de los voluminosos remates en forma de bellota o de escocia.

\section{EL TESORO Y SU SIGNIFICADO}

El tesoro de Monasterio de Rodilla con sus torques de ochos continuos, nudos de Hércules y cierres de gancho reafirma la teoría que los defiende como modelos originales de los talleres meseteños y constituye un buen ejemplo del alto nivel de desarrollo que llegó a alcanzar la orfebrería celtibérica. Ambos tipos de torques parecen responder a un momento evolucionado en su producción, en el que, posiblemente, se conjugasen satisfactoriamente los aspectos derivados del control técnico en la elaboración con el gusto por determinados elementos formales o decorativos plenamente aceptados.

El primer aspecto, el técnico, es perfectamente reconocible en una gran mayoría de objetos de adorno personal, como por ejemplo las arracadas. Estas piezas se caracterizan en la Celtiberia por sus cuerpos en forma de cuarto creciente, elaborados a base de hilos soldados, y su apéndice triangular de racimo. Ejemplares de este tipo aparecen en Palencia -tesoro de las Filipenses (Raddatz, 1969, 237) y Paredes de Nava (Palol, 1963, 241)-; en Zamora -Arrabalde I y II (Delibes, Martín Valls, 1982; Elorza, 1992, 30)—; Valladolid — tesoros de Padilla de Duero (Delibes, Esparza, Martín Valls, Sanz Mínguez, 1993, 435)-; León - hallazgo casual en Villacasabariego, cerca de Lancia (Celis Sánchez, 1993, 48) - y en Burgos - Roa, Monasterio de Rodilla, procedencia desconocida (Castillo, 1986, 250252) y Cerezo de Río Tirón ${ }^{5}$ - . La alta calidad técnica de algunas de estas piezas creemos que es indicativa de la perfección alcanzada en los trabajos de filigrana, por lo que no es difícil imaginar que se desarrollase la tendencia a fabricar joyas con alambres trenzados como los torques o los ya citados «adornos para el pelo» de Arrabalde, Saldaña y Sasamón ${ }^{6}$.

${ }^{5}$ Procedente de esta localidad ha ingresado en el Museo de Burgos, en concepto de depósito, un conjunto de piezas de orfebrería compuesto por 2 arracadas de oro, 2 anillos de oro (uno completo y otro fragmentado), una fíbula simétrica de plata y un fragmento de torques de plata (nota $n^{\circ} 3$ ).

${ }^{6}$ Los «adornos» se caracterizan, a diferencia de los torques, por sus cuerpos rígidos y compactos trenzados a partir de un junco central liso, rematándose en los que se conservan completos, Arrabalde y Saldaña, en cabezas estilizadas de caballo.
En lo relativo a las decoraciones ya hemos visto, al analizar sus posibles antecedentes, la aceptación de motivos mediterráneos que, en el caso concreto de la Meseta, contaron con un favorable sustrato cultural de elementos decorativos de raigambre céltica. Así por ejemplo los sogueados, presentes en el ornamento de algunas cerámicas y en diversos objetos de metal, bien pudieron facilitar la asimilación de piezas elaboradas con alambres enrollados; al igual que la pervivencia de la tradición en la torsión helicoidal de varillas, propia de la orfebrería del Bronce, en algunos torques meseteños, como el procedente de Jaramillo Quemado en Burgos (Castillo, 1986, 249), o el aparecido en la cercanías del Raso de Candeleda en Avila (Fernández, 1979, 396). Estas sociedades se caracterizaron por su tendencia a las decoraciones geométricas en armas y adornos, que en una etapa avanzada de la Segunda Edad del Hierro alcanzaron complicadas composiciones ${ }^{7}$. Así los motivos de «chevrons», las hiladas de «greneti», etc., aparecen indistintamente en las decoraciones de piezas de orfebrería, armas y objetos de adorno personal. Por su parte las composiciones geométricas, como por ejemplo la del tahalí damasquinado en plata de Arce-Mirapérez, fechado en el s. II a. C. (Ruiz Vélez, Elorza, 1991-1992), reproducen dibujos entrelazados que, a pesar de su trazo esquemático, se pueden definir como «ochos». Sin embargo, en la orfebrería de la Meseta concurren además otros elementos de clara raigambre mediterránea que, como ha quedado patente para el caso del nudo de Hércules (Delibes, Esparza, Martín Valls, Sanz Mínguez, 1993, 426), tienen una especial incidencia en sus producciones. Quizás las decoraciones de lazos y ochos, tan específicas de esta región, respondan a su tradición decorativa geométrica, cuya singularidad se afirma en la adaptación de sus motivos a los nuevos procedimientos técnicos, enrollado y trenzado de alambres, vinculados a la cultura ibérica y las corrientes mediterráneas.

La unión de ambos aspectos, el técnico y el decorativo, da lugar a unas piezas de apariencia complicada, pero de ejecución sencilla. La alternancia de diferentes formas de ejecución - trenzado y sogueado, lazos y sogueado, etc.- desarrolló esa tendencia hacia el barroquismo decorativo característico de la orfebrería celtibérica (Delibes, Esparza, $1989,124)$ y además pudo favorecer la creación de sus propios modelos, como los torques decorados con el nudo de Hércules y los de lazos y ochos.

\footnotetext{
7 Una tipología de estos motivos la realiza Beatriz de Griñó en su estudio «Los puñales de tipo Montevernorio-Miraveche. Un arma de la Segunda Edad del Hierro en la cuenca del Duero». BAR International series, 504 (I), Oxford, 1989.
} 
El hallazgo de varios atesoramientos en la Meseta Norte ha abierto nuevas expectativas en la investigación arqueológica, por una parte la consideración de la orfebrería celtibérica como una producción diferenciada y con entidad propia y por otra el valor documental que aporta en el estudio de estas sociedades (Delibes, Esparza, Martín Valls, Sanz Mínguez, 1993, 397 ss.).

La ocultación de este tesoro, a la vista del estado de conservación de las piezas, fue cuidadosa y por lo tanto suponemos que intencionada. Desconocemos, sin embargo, las causas y su finalidad por tratarse de un hallazgo casual sin ningún tipo de registro arqueológico. Las referencias a su aparición en las «cercanías» de Monasterio de Rodilla y los datos arqueológicos aportados por el yacimiento del Alto de Rodilla, son factores que nos han inclinado a pensar que ambos, tesoro y yacimiento, bien puedieran estar relacionados. En tales circunstancias esta ocultación sigue parámetros similares a las del resto de la Meseta Norte en cuanto a su localización cercana a lugares de poblamiento, o incluso - como en el de Raso de Candeleda (Fernández, 1986, 77) y del tesoro II de Padilla de Duero (Delibes, Esparza, Martín Valls, Sanz Mínguez, 1993, 413) - dentro de los propios poblados, enterrados bajo el suelo de viviendas. Esta asociación de tesoros-yacimientos es uno de los motivos que han inducido a considerar el carácter privado, de reunión de riqueza, de los tesoros celtibéricos.

Al igual que otros conjuntos meseteños (Delibes, Esparza, Martín Valls, Sanz Mínguez, 1993, 457) el de Monasterio de Rodilla, con sólo tres torques, parece responder también a una propiedad estrictamente personal, a lo sumo familiar, de objetos valiosos que, por su buena conservación, bien pudieron encontrarse en pleno uso cuando fueron escondidos.

Los tesoros celtibéricos aportan una nueva imagen social, de acumulación de riqueza privada, que se contrapone a la de pobreza y barbarie transmitida por los escritores clásicos. Estudios recientes sobre las fuentes escritas están permitiendo precisar que las relaciones de igualdad y comunidad no eran las características de los pueblos celtibéricos, sino que, por el contrario, existía la tendencia hacia las diferencias económicas, la concentración de la propiedad y el poder (Ruiz-Gálvez, 1991, 72-75). Quizás este proceso de cambio, caracterizado por la creación de nuevos asentamientos y por ciertas transformaciones en los rituales funerarios (Burillo, 1991, 25), sentó las bases para que surgiera una sociedad jerarquizada en la que la posesión de la riqueza pudo ser uno de sus símbolos de distinción (Delibes, Esparza, Martín Valls, Sanz Mínguez, 1993, 459).
La idea de igualdad social ha estado apoyada, en gran medida, por la uniformidad de los materiales arqueológicos de los ajuares funerarios de las necrópolis meseteñas. Sin embargo, la investigación actual ha abierto nuevas expectativas en su interpretación, dando a conocer la diferenciación de zonas dentro de las propias necrópolis y su posible intencionalidad de jerarquización social ${ }^{8}$. En este sentido algunos autores consideran que la uniformidad en la composición de los ajuares puede responder a un acto ritual (Delibes, Esparza, Martín Valls, Sanz Mínguez, 1993, 459), basado más en la tradición que en las diferencias sociales ${ }^{9}$. Quizás a este valor ritual se deba, igualmente, la ausencia de joyas en los enterramientos frente a la abundancia de materiales de hierro y bronce, en muchas ocasiones ricamente decorados con nihelados o láminas aplicadas de plata o de oro, como la guarda de un puñal de la tumba 27 de Villanueva de Teba, o la fíbula de la tumba 60 de Miraveche (Schüle, 1969, 290, la incluye dentro de la tumba 36). Sólo en casos muy concretos aparecen pequeñas piezas como los pendientes fusiformes de oro en Chamartín de la Sierra (Cabré, 1934, 353 ss.) o las joyas de plata en las necrópolis sorianas de la Mercadera (Taracena, 1932), Ucero (García-Soto, Castillo, 1990) y Carretiermes (Argente, 1991). Todos estos objetos - pulseras, pendientes o fíbulasse caracterizan por su sencillez, en contraste con la elaborada composición de las piezas de los tesoros.

\section{CRONOLOGÍA}

Como otros muchos hallazgos que carecen de contexto, la cronología de este tesoro plantea algunos problemas. Esta circunstancia sólo nos permite hacer una valoración comparada con otros hallazgos de la Meseta para los que, en base al numerario que los acompañaba, al menos se ha podido precisar la fecha aproximada de su ocultación. Según se deduce de los datos históricos de las fuentes literarias y de los datos arqueológicos, estas ocultaciones parecen responder a momentos de inestabilidad social provocada generalmente por las campañas de conquista que, para la cuenca del Duero y la Meseta

\footnotetext{
8 Estudios de Martín Valls (1984; 1986-87) para la zona palentina, la Osera y las Cogotas, o los realizados, por su parte, por Castro Martínez (1986) y Kurtz (1987) igualmente sobre las Cogotas.

${ }^{9}$ Bajo este aspecto podemos entender la presencia de pequeños vasos cerámicos elaborados a mano en la necrópolis burgalesa de Villanueva de Teba cuyos ajuares, caracterizados por sus ricas y abundantes piezas de bronce, se acompañan con urnas funerarias de funcionalidad puramente testimonial.
} 
Norte, discurren a lo largo del s. I a. C. Diversos son los acontecimientos bélicos que afectan a esta área, pero los de mayor repercusión social fueron las guerras sertorianas, que durante la década de los años 70 a. C. conmocionaron la zona media del Duero; la sublevación vaccea, con la conquista de Clunia por Metelo Nepote en el año 56 a. C. y, finalmente, la guerra contra cántabros y astures, iniciada hacia el año 29 a. C. por Estatilio Tauro y concluida en los primeros años del s. I de la era cristiana.

La situación de Tritium Autrigonum, relativamente marginal con respecto a la cuenca del Duero y en una zona de paso, nos inclina a pensar que quizás los acontecimientos bélicos que más le afectaron pudieron ser la rebelión de los vacceos y las campañas contra los cántabros. Tanto en un caso como en otro tuvieron repercusiones en los territorios de la provincia de Burgos y la ciudad de Tritium Autrigonum no sería ajena a la inestabilidad del momento.

Otro aspecto a tener en consideración es la tipología de los torques. Por sus caracteres encajan dentro de las producciones consideradas como más genuinamente celtibéricas, siendo sus paralelos más cercanos los torques de los tesoros de Padilla de Duero (Valladolid) y los de la ciudad de Palencia. Para los primeros se ha fijado su ocultación hacia la mitad del s. I a. C., en correspondencia con la sublevación vaccea (Delibes, Esparza, Martín Valls, Sanz Mínguez, 1993, 462), y para los segundos en torno al año 73 a. C. (Raddatz, 1969, 51-53). Por ello en nuestro caso, teniendo en cuenta su tipología y los momentos de inestabilidad de la zona, pensamos que su fecha de ocultación pudo ser hacia la segunda mitad del s. I a. C.

Más comprometido es intentar fijar el momento de su fabricación, para el cual si nos atenemos a las fechas de ocultación propuestas por Raddatz (1969, 53) para el tesoro de Menjíbar, entre el 105-90/80 a. C., en el que se incluyen torques decorados con nudo de Hércules, ochos y otro de alambres trenzados, debemos suponer que, al menos, a finales del s. II a. C. se podían estar elaborando piezas de estas características en la orfebrería prerromana de la Meseta Norte. Aunque quizás los torques con trenzado de ochos continuos, por su compleja composición decorativa, pudieran ser posteriores.

\section{BIBLIOGRAFÍA}

AbÁsolo Álvarez, J. A. (1975): Comunicaciones en la época romana en la provincia de Burgos. Burgos.
Abásolo Álvarez, J. A.; Alonso, J. M.; Sainz, F. (1982): «Nuevas inscripciones romanas procedentes de Briongos, Monasterio de Rodilla». Boletín de la Institución Fernán González, 1: 161168.

Almagro Basch, M. (1970): «Las joyas del Cerro de la Miranda (Palencia)». Memorias de los $\mathrm{Mu}$ seos Arqueológicos Provinciales, 1955-57: 3149.

Almagro Gorbea, M. (1989): «Orfebrería orientalizante», en El Oro en la España prerromana. Monografía de Revista de Arqueología: 68-81.

- (1991): «I Celti della peninsola iberica», en I Celti, Catálogo-exposición, Palazzo Grassi, Venezia-Milano: 389-405.

Alonso, J. M. (1972): «Elementos romanos de la antigua Tritium». Zephyrus XXIII-XXI: 209220.

Argente Oliver, J. L.; Díaz Díaz, A; Bescós CoRRAL, A. (1991): Tiermes. Excavaciones Arqueológicas, campaña 1991. Junta de Castilla y León-Iberdrola. Soria.

Burillo Mozota, F. (1991): «Los celtíberos». Los celtas en la Península Ibérica. Monografía de Revista de Arqueología: 18-25.

CABré Aguiló, J. (1934): «Guerreros indígenas de la Edad del Hierro, de la Península Ibérica, con pendientes de oro». Las Ciencias 1: 353-358.

Castillo Iglesias, B. (1985): «Joyería antigua prerromana en la provincia de Burgos». Numantia II: 247-256.

Castro Martínez, P. V. (1986): «Organización espacial y jerarquización social en las necrópolis de las Cogotas (Ávila)». Coloquio sobre el microespacio 3. Del Bronce Final a la Epoca Ibérica. Teruel 1984. Arqueología Espacial, 9. Teruel: 127-137.

Celis Sánchez, J. (1993): en Museo de León. Guíal Catálogo de 100 piezas. Junta de Castilla y León. Valladolid.

Cristofani, M.; Martelli, M. (1983): L'oro degli Etruschi. Instituto Geografico de Agostini, Novara.

Delibes de Castro, G.; Martín Valls, R. (1982): $E l$ tesoro de Arrabalde y su entorno histórico. Catálogo-Exposición, Zamora.

Delibes de Castro, G.; Esparza Arroyo, A. (1989): «Los tesoros prerromanos de la Meseta Norte y la orfebrería celtibérica», en El Oro en la España prerromana. Monografía de Revista de Arqueología: 108-129.

Delibes de Castro, G.; Esparza Arroyo, A.; Martín Valls, R.; SAnz Mínguez, C. (1993): «Tesoros celtibéricos de Padilla de Duero». Arqueolo- 
gía Vaccea. Estudios sobre el mundo prerromano en la cuenca media del Duero. Valladolid: 397-470.

DEPPERT-LIPPITZ, B. (1985): Griechischer Goldschmuck. Kulturgeschichte der Antiken Welt 27. Mainz am Rhein.

Elorza GuineA, J. C. (1992): «Tesoros de Arrabalde», en Tesoros de Castilla y León. De la Prehistoria a los Reyes Católicos. Catálogo-exposición Pabecal, Sevilla. Madrid: 30-43.

EsParZa Arroyo, A. 1983: «Joyas celtibéricas de Zamora en el Museo Británico». BSEAA, XLIX: $39-46$.

- (1988): «Materiales de la Edad del Hierro», en La colección arqueológica del Padre Saturio González en Santo Domingo de Silos. Burgos: 115-158.

FERnÁNDEZ GómEz, F. (1979): «Un tesorillo de plata en el castro de El Raso de Candeleda (Ávila)». TP, 36: 379-398.

- (1985): «El tesorillo turdetano de Mairena del Alcor (Sevilla)». TP, 42: 149-194.

- (1986): Excavaciones arqueológicas en el Raso de Candeleda. Diputación de Ávila. Ávila.

- (1989): «Orfebrería indígena en época prerromana», en El Oro en la España prerromana. Monografía de Revista de Arqueología: 82-89.

Formigli, E. (1983): «Appendice tecnica», en L'Oro degli Etruschi. Istituto Geografico de Agostini. Novara: 321-333.

García Soto, E.; Castillo, B. (1990): «Una tumba excepcional de la necrópolis celtibérica de Ucero (Soria)». Necrópolis celtibéricas, II Simposio sobre los Celtíberos, Daroca, 1988. Zaragoza: 59-64.

GonZÁlEZ SALAS, S.: (1953) «Inventario arqueológico». NAH, I, 1-3: 226.

Herrero Martínez de Azcoitia, G. (1969): «Las fíbulas con cabezas de caballo del Museo Arqueológico Provincial de Palencia». BSEAA, XXXIVXXXV: 321-323.

I Celti (1991): Catálogo-Exposición, Palazzo Grassi, Venezia-Milano.

KuRTZ, W. (1987): La necrópolis de las Cogotas. Vol. I, Ajuares. British Archaeological Reports, International Series, 344. Oxford.

LóPez Cuevillas, F. (1951): Las joyas castreñas. Madrid.

Luis Monteverde, J. (1969): «La colección Monteverde de Burgos». NAH, X-XI-XII, 1966-68: 225-234.

MAÑANES, T. (1983): Arqueología vallisoletana II.
Torozos, Pisuerga y Cerrato (Estudios Arqueológicos en la Cuenca del Duero). Valladolid.

MarTín Valls, R. (1984): «Prehistoria palentina». Historia de Palencia, I. Edades Antigua y $\mathrm{Me}$ dia. Palencia: 169-175.

- (1986-87): «La segunda Edad del Hierro: consideraciones sobre su periorización». Actas (19861987): 59-86.

Martín Valls, R.; Delibes de Castro, G. (1981): «Hallazgos arqueológicos en la provincia de $\mathrm{Za}-$ mora VIII» BSEAA, XLVII: 154-186.

- (1982) El tesoro de Arrabalde y su entorno histórico. Zamora.

MÉLIDA, J. R. (1902): «Antigüedades anterromanas de la costa de Levante». RABM, VII: 164-174.

- (1905): «El tesoro ibérico de Jávea». RABM, XIII: 363-373.

Nicolini, G. (1990): Techniques des ors antiques. La bijouterie ibérique du VII au IV siècle. Paris.

Osaba y Ruiz DE Erenchun, B. (1964): «Catálogo arqueológico de la provincia de Burgos». NAH, VI, 1-3, 1962: 227-277.

Palol, P. (1963): «Dos arracadas de Paredes de Nava (Palencia)». BSEAA, XXIX: 239-246.

Perea, A. (1991): Orfebrería prerromana. La arqueología del oro. Madrid.

RadDATZ, K. (1969): Die Schatzfunde der Iberischen Halbinsel. Madrider Forschungen 5. Berlin.

Ruiz Vélez, I.; Elorza Guinea, J. C. (1991-1992): «Tahalí damasquinado en plata de Miranda de Ebro (Burgos)». Zephyrus XLIV-XLV: 579586.

Ruiz-Gálvez Priego, M. (1991): «La economía celtibérica», Los celtas en la Península Ibérica. Monografía de Revista de Arqueología: 7275.

SCHÜLE, W. (1969): Die Meseta-Kulturen der Iberischen Halbinsel. Madrider Forschungen 3. Berlin.

Taracena Aguirre, B. (1932): Excavaciones en la Provincia de Soria. La Necrópolis de la Mercadera. JSEA n ${ }^{\circ} 119$. Madrid.

- (1943): «Cabezas trofeo en la España céltica». AEspA, XVI, 51: 157-171.

Tarradell, M. (1968): Arte Ibérico. Barcelona.

VV.AA. (1985): Historia de Burgos. Tomo I: La Edad Antigua. Burgos.

Williams, D.; Odgen, J. (1994): Greek gold. Jewellery of the Classical World. British Museum, London. 